\title{
Growth responses of seedlings produced by parent seeds from specific altitudes
}

\author{
Valasia Iakovoglou ${ }^{1}$ Ioannis Takos ${ }^{1} \cdot$ \\ Georgia Pantazi ${ }^{1} \cdot$ Aikaterini Pipsou $^{1}$ • \\ Maria Neofotistou ${ }^{1}$
}

Received: 11 January 2018 / Accepted: 19 April 2018 / Published online: 16 October 2019

(C) The Author(s) 2019

\begin{abstract}
Restoration activities in semi-arid Mediterranean areas like Greece face many obstacles, such as summer droughts that are becoming more intense with climate change, that pose limitations to transplanting success. Seedlings for restoration must be of high quality; a vigorous root system is critical to enable seedlings to tolerate adverse conditions. Here we investigated the effects of altitude and source parent for seeds on the growth of subsequent seedlings to determine the best seed sources for obtaining highest-quality, most-tolerant seedlings for restoration efforts. Seeds of Quercus coccifera L. were collected on an altitudinal gradient of $50 \mathrm{~m}$ (200, 250 and $300 \mathrm{~m}$ a.s.1.) and from specific parents at each altitude. Subsequent seedlings were grown for 3 months in a greenhouse with controlled irrigation. The results indicated a strong altitudinal and parental seed effect on seedling characteristics. As altitude decreased, biomass of the seedlings increased, and they developed more vigorous roots and more photosynthetic leaf tissue. Thus, altitude and parent are critical factors to consider when producing seed-derived seedling. By collecting seeds from a specific altitude and parent, more vigorous and stresstolerant seedlings can be obtained to enhance transplanting success.
\end{abstract}

The online version is available at http://www.springerlink.com

Corresponding editor: Zhu Hong.

Valasia Iakovoglou

viakovoglou@yahoo.com

1 Department of Forestry and Natural Environment Management, Eastern Macedonia and Thrace Institute of Technology (EMaTTECH), 66100 Drama, Greece
Keywords Climate change $\cdot$ Conservation $\cdot$ Nursery practices $\cdot$ Regeneration $\cdot$ Seedling physiology

\section{Introduction}

Reforestation efforts in semi-arid Mediterranean areas such as Greece are usually associated with high mortality levels, mainly due to intense and frequent drought events, especially during the summer. Such drought events have been predicted to increase in severity and duration at an alarming level (Xoplaki et al. 2005; Lionello et al. 2006; IPCC 2013). Climate change is thus expected not only to pose obstacles to reforestation efforts (Villar-Salvador et al. 1999; Rude 2007) and the growth of the species (Olivar et al. 2015), but also to threaten the species existence when they cannot adapt quickly to abrupt climatic alterations (Gritti et al. 2006; Allen et al. 2010; Thomas and Garcia-Marti 2015). The ecological responses of a species to adapt and perpetuate is associated with a shift in its distributional range toward higher latitudes and altitudes (Korpel et al. 1982; Penuelas and Boada 2003; Saha et al. 2016).

Specific characteristics such as vigorous roots enable seedlings to overcome transplanting stress that is usually associated with water deficit, a common problem in Mediterranean ecosystems (Bellot et al. 2002; David et al. 2016). Extensive root systems favor faster absorption and enhanced exploration into a wider area and greater soil depth for water and nutrients (Ackerly 2004; Villar-Salvador et al. 2005; Lambers et al. 2006; Mitchell et al. 2008). Factors such as the parental seed source and seed size can also influence the attributes of the generated seedlings; larger seeds produce more vigorous seedlings (Iakovoglou et al. 2007; Iakovoglou et al. 2008). In addition, as altitude increases, trees become more stunted, and seed production and germination 
percentage decrease (Mencuccini et al. 1995; Robakowski et al. 1997; Loha et al. 2006; Coomes and Allen 2007). Research has also indicated that in terms of seedling growth and biomass allocation, seed sources from lower altitudes resulted to more vigorous seedlings (Dierig et al. 2006; Iakovoglou et al. 2017), while in other cases the results were contradictory (Liu et al. 2016). Nonetheless, to our knowledge, limited research has been conducted in addressing the effect of altitudinal seed sampling gradient on the characteristic of the produced seedlings for Mediterranean broadleaved species.

Here we investigated the growth traits of Quercus coccifera L. (kermes oak; Fagaceae) seedlings in relation to the altitude and parent origin of the seed. We hypothesized that both altitude and parent would affect growth of the seedlings, with an increase in altitude associated with reduced seedling growth. By studying the impact of seeds gathered on an altitude gradient on subsequent seedling growth, we can gain insights that will guide nurseries when collecting seeds at a specific altitude to generate seedlings with growth traits such as vigorous root systems that will favor tolerance to adverse conditions and thus increase transplanting success in reforestation efforts.

\section{Material and methods}

\section{Seed collection}

Quercus coccifera was selected because it is an evergreen, sclerophyllous, broadleaved species that thrives in Mediterranean semi-arid ecosystems (Cañellas and San Miguel 2000). It is usually found in a shrubby form, mainly due to intense grazing activities. It can tolerate intensely adverse growth conditions and maintain its vigor under poor and dry soils (Papatheodorou et al. 1998; Konstantinidis et al. 2005). This is mainly due to its ability to grow vigorous root systems that enable the species to better exploit water and nutrient resources (Benayas et al. 2007; Verdaguer et al. 2011). Consequently, it is ecologically very valuable, since it provides food and shelter to the wildlife and livestock in areas where other species fail (Benayas et al. 2007), while its vigorous roots and thick foliage prevent soil erosion (Cañellas and San Miguel 2000).

Before seed collection, at least 60 open-crown (crown growth not limited by competitive plants), healthy $Q$. coccifera shrubs (20 at each altitude) were closely monitored and marked to guarantee an adequate number of seeds for the experiment. Seeds were collected on an altitudinal gradient of $50 \mathrm{~m}(200,250$ and $300 \mathrm{~m}$ a.s.l.) and only from a westfacing aspect $\left(24^{\circ} 09^{\prime}, 41^{\circ} 08^{\prime}\right)$ in northern Greece to minimize climatic variation, particularly from rainfall events, that substantially affect the size and number of seeds produced and plant growth. The main collection criterion was seed color; brown is a good indicator of proper seed maturity (Bonner and Vozzo 1987).

After seed collection (20 trees per altitude), healthyappearing seeds were placed in water for a $24-\mathrm{h}$ imbibition; damaged and insect-infested seeds were discarded (Bonner and Vozzo 1987; Gribko and Jones 1995). For each parent at each altitude, the seeds were separated based on their widest diameter by using digital calipers and were placed in polyethylene bags (Gosling 1989), then cold-stratified at 4 $\pm 1{ }^{\circ} \mathrm{C}$ for 4 months to break seed dormancy. Only pre-germinated seeds with a maximum diameter of $12-4 \mathrm{~mm}$ were sown to minimize any seed-size effect on seedling growth (Iakovoglou et al. 2007; Iakovoglou et al. 2008). Of the 20 closely monitored shrubs, four parents per altitude provided adequate pre-germinated seeds to complete the experiment. The seeds were sown in containers $(1.5 \mathrm{~L})$ of a $3: 1$ peat to perlite mixture. The seedlings were grown for 3 months in a greenhouse $\left(\sim 25^{\circ} \mathrm{C}\right)$ with consistent daily irrigation and no fertilization.

\section{Studied variables}

At the end of 3 months, eight seedlings from each parent at each altitude (96 total seedlings) were harvested. After careful removal of the soil substrate, the seedlings were separated into their subparts and evaluated. Leaf area (LA) was measured by using a leaf area meter (AM 100, ADC Bioscientific, Herts, UK). Dry mass (g) of the seedlings and their subparts (leaves [LDW], stem (STDW] and roots $[R D W])$. Total dry mass of the shoot (SDW) was determined as LDW + STDW, and total seedling dry mass (TSDW) was estimated by the partitioning of LDW+STDW+RDW (Iakovoglou et al. 2008). The ratio of root to shoot dry mass (RDW/SDW) was estimated and specific leaf area (SLA) was calculated as the ratio of the leaf area to leaf dry mass (LA/LDW). The percentage of biomass allocation to the leaves (LDW/TSDW), stems (STDW/TSDW) and roots (RDW/TSDW) was also calculated.

\section{Statistical analyses}

One-way ANOVA was used to compare means of various traits of seedlings among the three altitudes with the program SPSS v. 15.0 (SPSS, Chicago, IL, USA). Data were tested for normality and homogeneity. The general linear model was used to determine the effect of altitude, parent and their interaction. Mean differences were tested with the Tukey's multiple range tests at significance levels of $p<$ $0.01(* *)$ and $p<0.05(*)$. Pearson's correlation analysis was performed to determine the significance of the relationship among the studied variables 


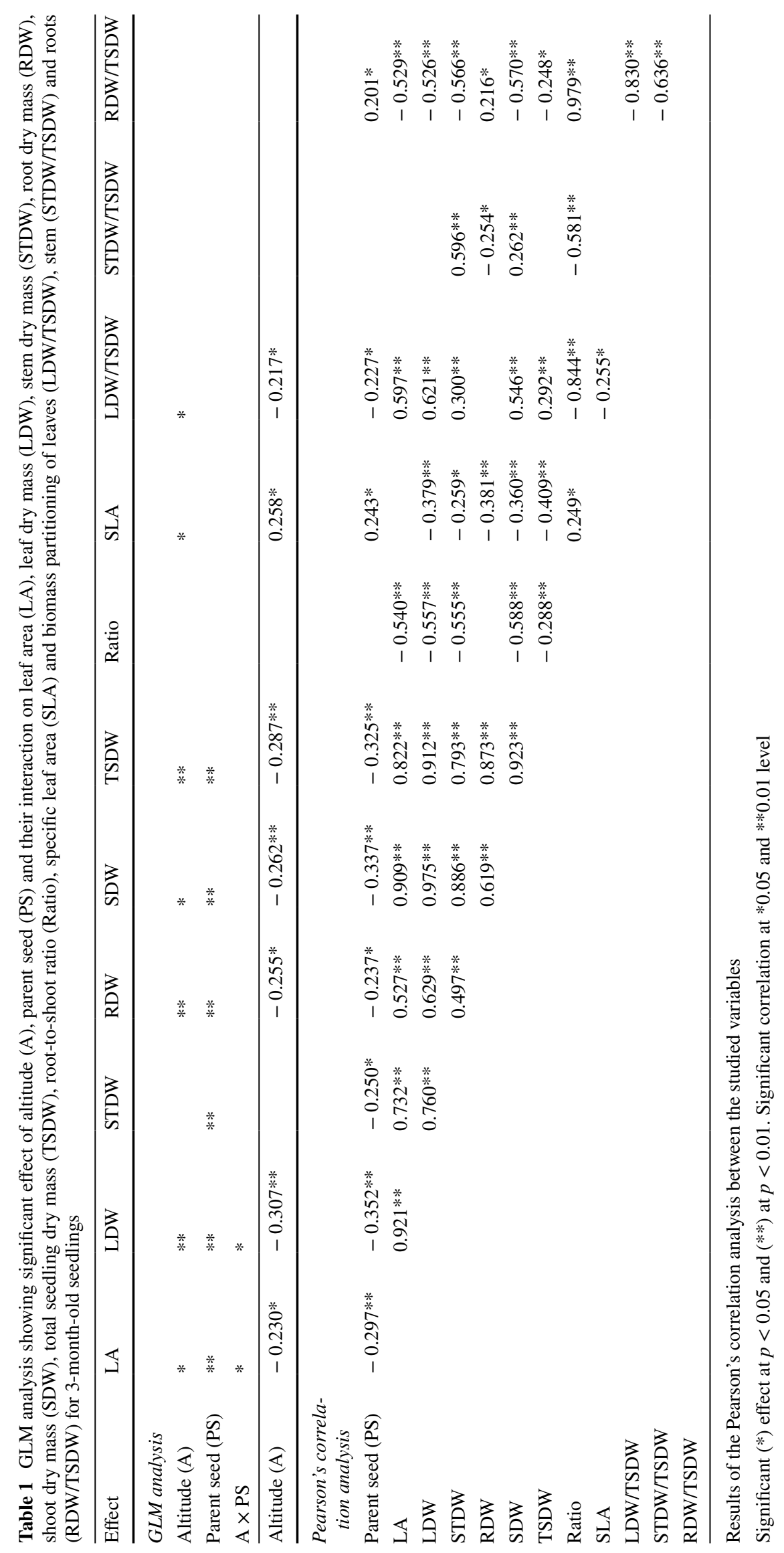



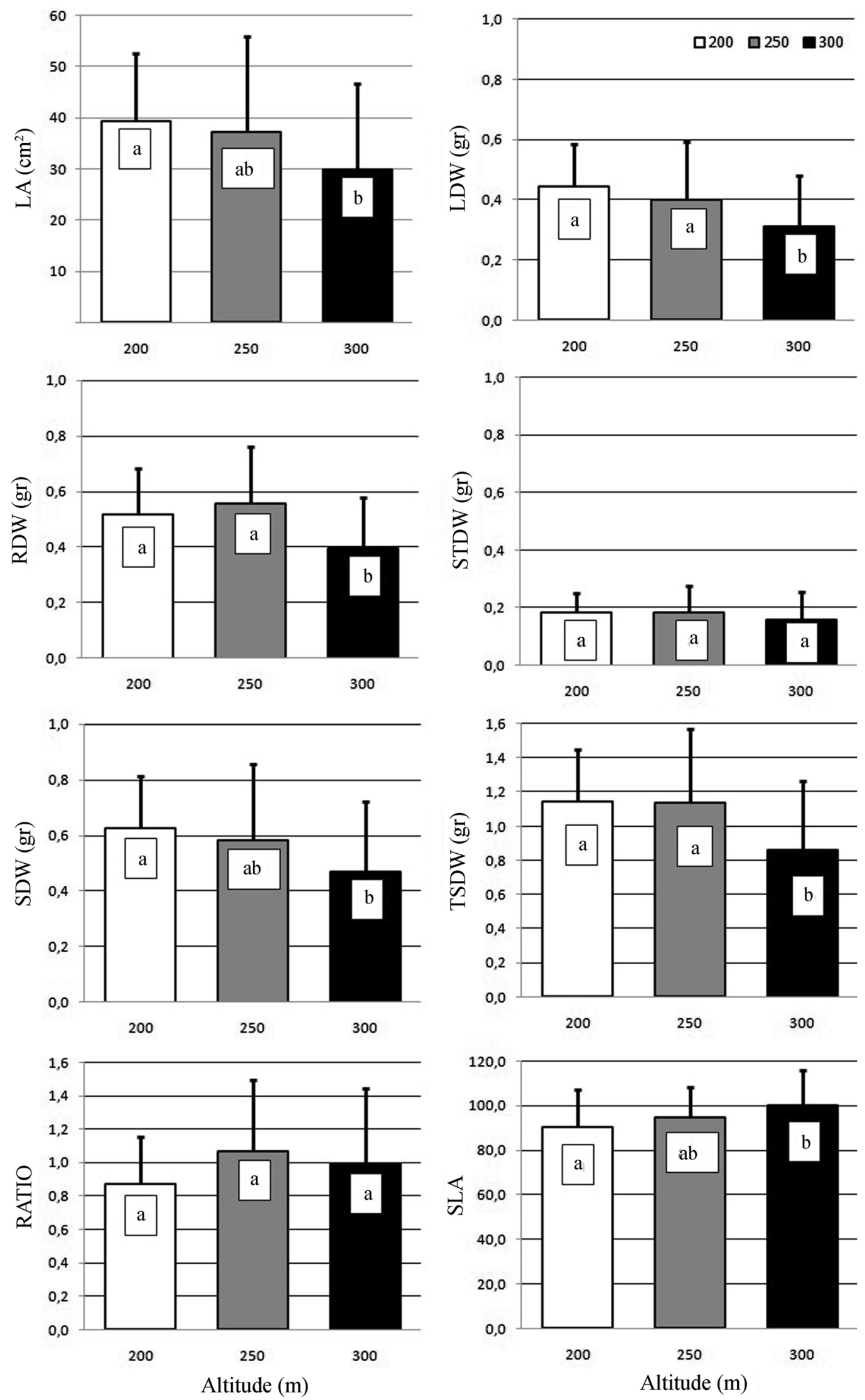
4Fig. 1 The effect of altitude ( $m$ a.s.1.) on growth traits of 3-monthold seedlings. The studied growth traits were the leaf area (LA), dry mass of leaves (LDW), stems (STDW), roots (RDW), shoots (SDW), total dry mass of seedlings (TSDW), root to shoot ratio (Ratio) and specific leaf area (SLA). Different letters indicate significant differences among altitudes for each variable at $p<0.05$

\section{Results}

There was a strong effect of both the altitude and parent on the majority of the studied variables. Specifically, the altitudinal gradient affected LA, LDW, RDW, SDW, TSDW, SLA and LDW/TSDW (Table 1A). Similarly, a parental effect was evident for the LA, LDW, STDW, RDW, SDW and TSDW, with an interaction effect for the LA and LDW. Based on the Pearson's correlation analysis results, both the altitude and parent tree were negatively correlated with LA, LDW, RDW, SDW, TSDW and LDW/TSDW, with the parent also being negatively correlated with the STDW (Table 1B).

Seedlings derived from seeds from lower altitudes had greater mean values for all growth traits (LA, LDW, RDW, SDW and TSDW) except SLA compared with those from seedlings from seeds from higher altitudes (Fig. 1).

The effect of altitude was also supported by the results of the percentage allocations of biomass (Fig. 2). Seedlings derived from seed sources of lower altitudes (200 $\mathrm{m}$ a.s.1.) had greater LDW than those of the higher altitudes (250 and $300 \mathrm{~m}$ a.s.1.), whereas altitude did not significantly affect the percentage of allocation to stems or roots.

\section{Discussion}

Altitude and parent seed source had a strong effect on the growth of $Q$. coccifera seedlings (Table $1 \mathrm{~A}$ ); the altitudinal effect was greater, with seedlings from seeds at lower altitudes outperforming those from higher altitude sources (Fig. 1). Thus, even just a 50-m difference in altitude affected growth traits of the seedlings. These results coincide with results for seedlings of $Q$. coccifera from seeds along an altitudinal gradient of $100 \mathrm{~m}$ (Iakovoglou et al. 2017) and for Pinus flexilis (Reinhardt et al. 2011). Pearson's correlation analysis also supported these results with a negative correlation among altitude and all but one trait (LA, LDW, RDW, SDW, TSDW and the LDW/TSDW); SLA was positively correlated (Table 1B). These results show that altitude is a strong factor that should always be considered when collecting seeds for seedling production, since specific characteristics such as more vigorous root systems are associated with lower altitude seed sources.

Particularly for $Q$. coccifera, which is characterized by its vigorous root systems (Benayas et al. 2007; Verdaguer et al.
2011), seedlings from seeds from lower altitudes allocated more of the total biomass to the root systems. Seedlings with vigorous root systems can take up more water and nutrients, which coincides with potentially greater reforestation success (Bellot et al. 2002). So, particularly for semi-arid Mediterranean areas such as Greece, those seedlings with better root systems are better equipped to grow in stressful conditions, particularly droughts, when regenerating a site, and transplanting success should potentially increase.

Further, the greater leaf area and leaf dry mass for $Q$. coccifera of seedlings from the lower altitudinal sources indicates that those seedlings are better equipped for light harvesting. Nonetheless, those seedlings were also characterized by lower SLA values, indicating that they had thicker leaves, which enables the species to adapt and tolerate adverse growth conditions (Coomes and Allen 2007). Because leaf characteristics for species such as $Q$. coccifera are related to the overall seedling performance, leaf measurements such as LA and SLA, could be used as a less-labor intensive measure to estimate seedling growth than rootrelated traits. Those results were also supported by Pearson's correlation analysis, which showed that the leaf characteristics LA and LDW were positively correlated with the majority of the other seedling characteristics (STDW, RDW, SDW, TSDW and LDW/TSDW), but negatively correlated to the Ratio and the RDW/TSDW (Table 1B).

The effect of altitude on the characteristics of the produced seedlings was also evident by the percentage of biomass allocation (Fig. 2). So, leaf biomass allocation differed among altitudes, with greater mean value for the lower altitude of $200 \mathrm{~m}$ a.s.1. This result shows that, even for $Q$. coccifera in which vigorous roots play a dominant role in shaping the physiological ability of the species to thrive under harsh environments, leaves also play a crucial role in survival.

Similar to the altitudinal effect, a parental effect was evident for the majority of the studied variables (LA, LDW, STDW, RDW, SDW and TSDW) (Table 1A), coincident with results for Quercus macrocarpa and Q. alba (Iakovoglou et al. 2007, 2008). Although we minimized the impact of climatic and edaphic variations on the seeds by selecting parents that were growing near each other on the same westfacing aspect, the parental effect was still evident. These results were also supported by the Pearson's correlation analysis where "parent" was correlated with nine of the 11 studied variables (Table 1B). These correlations with the parent might indicate that pre-selected genetic attributes enable the survival and competitiveness of those parents at a specific altitude (Tang and Ide 2001; Nakagawa 2003). Those attributes were passed to the produced seeds, enabling seedling growth with specific characteristics (such as more vigorous root systems) that made them more competitive than other seedlings. Consequently, careful selection of 


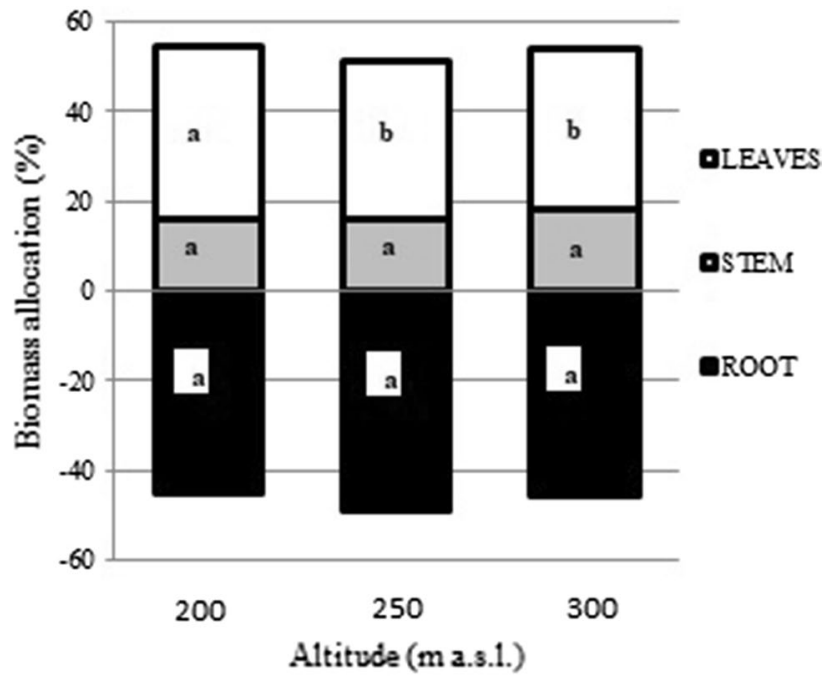

Fig. 2 Percentage of biomass allocation for seedlings derived from seeds at three altitudes (200, 250 and $300 \mathrm{~m}$ a.s.1.). Different letters indicate significant differences among altitudes for each variable at $p$ $<0.05$

vigorous parent trees is critical to generate vigorous seedlings that have larger root systems and more leaf area.

Based on the results of our study, collecting seeds from lower altitudes is recommended for obtaining more vigorous seedlings, especially to increase transplanting success when regenerating areas with adverse conditions such as severe droughts. Hence, this research provides foundation for future research on growing seedlings to restore higher altitude sites and determining whether the genetic characteristics of a less-fit high-altitude seedlings are worth conserving. Further research should include a wider variety of species and stresses (e.g., water deficit) to increase transplanting success and productivity of certain forest species when challenged by climatic change.

\section{Conclusion}

In this study of the effect of altitudinal seed source and parent on growth traits of the resultant seedlings, an altitudinal gradient of $50 \mathrm{~m}$ was sufficient to influence growth of the seedlings, even though climatic and edaphic variation was minimized by sampling specific-sized seed from a westfacing aspect. Seeds from lower altitudes produced more vigorous seedlings, with greater root systems for enhanced water absorption and more leaf area for greater photosynthetic capacity, as opposed to higher altitudes. Further, leaf characteristics (e.g., SLA) indicated that those seedlings could better cope and tolerate abrupt climatic alterations, particularly droughts. Thus, for $Q$. coccifera, seeds should be harvested from lower altitudes to provide more vigorous seedlings that are better equipped (vigorous roots and thicker leaves) to tolerate water deficits and thus increase regeneration success. Future research on more and diverse species should help expand our knowledge on the altitudinal effects on parent seeds and subsequent seedling growth.

Open Access This article is distributed under the terms of the Creative Commons Attribution 4.0 International License (http://creativeco mmons.org/licenses/by/4.0/), which permits unrestricted use, distribution, and reproduction in any medium, provided you give appropriate credit to the original author(s) and the source, provide a link to the Creative Commons license, and indicate if changes were made.

\section{References}

Ackerly D (2004) Functional strategies of chaparral shrubs in relation to seasonal water deficit and disturbance. Ecol Monogr 74:25-44

Allen CD, Macalady AK, Chenchouni H, Bachelet D, Mc-Dowell N, Vennetier M, Kitzberger T, Rigling A, Breshears DD, Hogg EH, Gonzalez P, Fensham R, Zhang Z, Castro J, Demidova N, Lim J-H, Allard G, Running SW, Semerci A, Cobb N (2010) A global overview of drought and heat-induced tree mortality reveals emerging climate change risks for forests. For Ecol Manag 259:660-684

Bellot J, Ortiz de Urbina JM, Boner A, Sánchez JR (2002) The effects of treeshelters on the growth of Quercus coccifera $\mathrm{L}$. seedlings in a semiarid environment. Forestry 75(1):89-106

Benayas JMR, Fernández A, Aubenau A (2007) Clipping herbaceous vegetation improves early performance of planted seedlings of the Mediterranean shrub Quercus coccifera. Web Ecol 7:120-131

Bonner FT, Vozzo JA. 1987. Seed biology and technology of Quercus. General Technical Report SO-66, p 11. USDA Forest Service, Southern Forest Experiment Station. New Orleans: New Orleans, LA

Cañellas I, San Miguel A (2000) Biomass of root and shoot systems of Quercus coccifera shrublands in Eastern Spain. Ann For Sci 57:803-810

Coomes DA, Allen RB (2007) Effects of size, competition and altitude on tree growth. J Ecol 95:1084-1097

David TS, Pinto CA, Nadezhdina N, David JS (2016) Water and forests in the Mediterranean hot climate zone: a review based on a hydraulic interpretation of tree functioning. For Syst 25(2):1-14

Dierig DA, Adam NR, Mackey BE, Dahlquist GH, Coffelt TA (2006) Temperature and elevation effects on plant growth, development. Ind Crops Prod 24:17-25

Gosling PG (1989) The effect of drying Quercus robur acorns to different moisture contents, followed by storage, either with or without imbibition. Forestry 62:41-50

Gribko LS, Jones WE (1995) Test of the float methods of assessing northern red oak acorn condition. Tree Planters' Notes 46:143-147

Gritti ES, Smith B, Sykes MT (2006) Vulnerability of Mediterranean Basin ecosystems to climate change and invasion by exotic plant species. J Biogeogr 33:145-157

Iakovoglou V, Aslanidis K, Zaimes GN (2017) Quercus coccifera growth as affected by altitudinal seed-sampling gradient. Fresenius Environ Bull 26(2):1234-1239

Iakovoglou V, Hall RB, Misra MK, Knapp AD (2008) Significance of seed size and parent on biomass, and morphological variables of Quercus macrocarpa and Q. alba. Seed Technol 30:45-59 
Iakovoglou V, Misra MK, Hall RB, Knapp AD (2007) The effect of seed size and parent tree on seed variables and seedling growth of Quercus macrocarpa and Q. alba. Seed Sci Technol 35:771-777

IPCC (2013) Climate change 2013. The physical science basis. Contribution of working group I to the fifth assessment report of the intergovernmental panel on climate change, p 1535. Cambridge University Press, New York

Konstantinidis P, Tsiourlis G, Galatsidaw S (2005) Effects of wildfire season on the resprouting of kermes oak (Quercus coccifera $\mathrm{L}$.). For Ecol Manag 208:15-27

Korpel S, Paule L, Laffers I (1982) Genetics and breeding of the silver fir (Abies alba MILL.). Ann For 9(5):151-184

Lamber H, Shane MW, Cramer MD, Pearse SJ, Veneklaas EJ (2006) Root structure and functioning for efficient acquisition of phosphorus: Matching morphological and physiological traits. Ann Bot 98(4):693-713

Lionello P, Rizzoli Malanotte-, Boscolo R, Alpert P, Artale V, Li L, Luterbacher J, May W, Trigo R, Tsimplis M, Ulbrich U, Xoplaki E (2006) The Mediterranean climate: an overview of the main characteristics and issues. Dev Earth Environ Sci 4:1-26

Liu N, Wang T, Feng Q, Guo J, Zhang Y, Wang J (2016) Transplantation of Larix principis rupprechtii Mayr. and Picea meyeri Rehd. Seedlings to low altitude and two contrasting light environments reveals climate warming effects on early seedling performance. Scand J For Res 31:46-55

Loha A, Tigabu M, Teketay D, Lundkvist K, Fries A (2006) Provenance variation in seed morphometric traits, germination, and seedling growth of Cordia Africana Lam. New For 32:71-86

Mencuccini M, Piussi P, Zanzi Sulli P (1995) Thirty years of seed production in a subalpine Norway spruce forest: Patterns of temporal and spatial variation. For Ecol Manag 76:109-125

Mitchell PJ, Veneklass EJ, Lambers H, Burgess SSO (2008) Leaf water relations during summer water deficit: differential responses in turgor maintenance and variation in leaf structure among different plant communities in south-western Australia. Plant Cell Environ 31:1791-1802

Nakagawa M (2003) Effect of seed source elevation on bud opening of Yezo spruce (Picea jezoensis). J For Res 8(4):267-270

Olivar J,Bogino S, Spiecker H., Bravo F (2015) Changes in climategrowth relationships and IADF formation over time of pine species (Pinus halepensis, $P$. pinaster and P. sylvestris) in Mediterranean environments. For Syst 24(1):1-9

Papatheodorou EM, Pantis JD, Stamou GP (1998) The effect of grazing on phenology and biomass allocation in Quercus coccifera (L.). Acta Oecol 19(4):339-347.
Peñuelas J, Boada M (2003) A global change-induced biome shift in the Montseny Mountains (NE Spain). Global Change Biol 9:131-140

Reinhardt K, Castanha C, Germino MJ, Kueppers LM (2011) Ecophysiological variation in two provenances of Pinus flexilis seedlings across an elevation gradient from forest to alpine. Tree Physiol $1: 1-11$

Robakowski P, Modrzynski J, Idris M (1997) Adaptation of seedling to the altitude: a case of the Norway spruce from the Polish sudety mountains. Pirineos Pirineos 149-150:81-89

Rude $\mathrm{Ph}$ (2007) Mediterranean climate ecosystems. Encycl Biodivers 3:1-15

Saha S, Rajwar G-S, Kumar M (2016) Forest structure, diversity and regeneration potential along altitudinal gradient in Dhanaulti of Garhwal Himalaya. For Syst 25(2):1-15

SPSS (2006) Rel. 15.0, Brief guide, p 191. SPSS, Chicago

Tang D-Q, Ide Y (2001) Genetic variation in fruitfulness in a hinoki (Chamaecyparis obtuse Endl.) seed orchard and its impact on the maintenance of genetic diversity in seedlots. J For Res 6(2):67-72

Thomas PA, Garcia-Marti X (2015) Response of European yews to climate change: a review. For Syst 24(3):1-15

Verdaguer D, Vilagran J, Lloansi S, Fleck I (2011) Morphological and physiological acclimation of Quercus coccifera $\mathrm{L}$. seedlings to water availability and growing medium. New For 42:363-381

Villar-Salvador P, Ocaña L, Peñuelas J, Carrasco L (1999) Effect of water stress conditioning on the water relations, root growth capacity, and the nitrogen and non-structural carbohydrate concentration of Pinus halepensis Mill. (Aleppo pine) seedlings. Ann For Sci 56:459-465

Villar-Salvador P, Peñuelas J, Peñuelas JL, Planelles R (2005) Effect of nitrogen fertilization in the nursery on the drought and frost resistance of Mediterranean forest species. Invest Agrar Sist Recur For 14(3):408-418

Wilson JP, Thomson K, Hodson GJ (1999) Specific leaf area and leaf dry matter content as alternative predictors of plant strategies. New Phytol 143:155-162

Xoplaki E, Luterbacher J, Paeth H, Dietrich D, Steiner N, Grosjean M, Wanner H (2005) European spring and autumn temperature variability and change of extremes over the last half millennium. Geophys Res Lett 32:1-4

Publisher's Note Springer Nature remains neutral with regard to jurisdictional claims in published maps and institutional affiliations. 